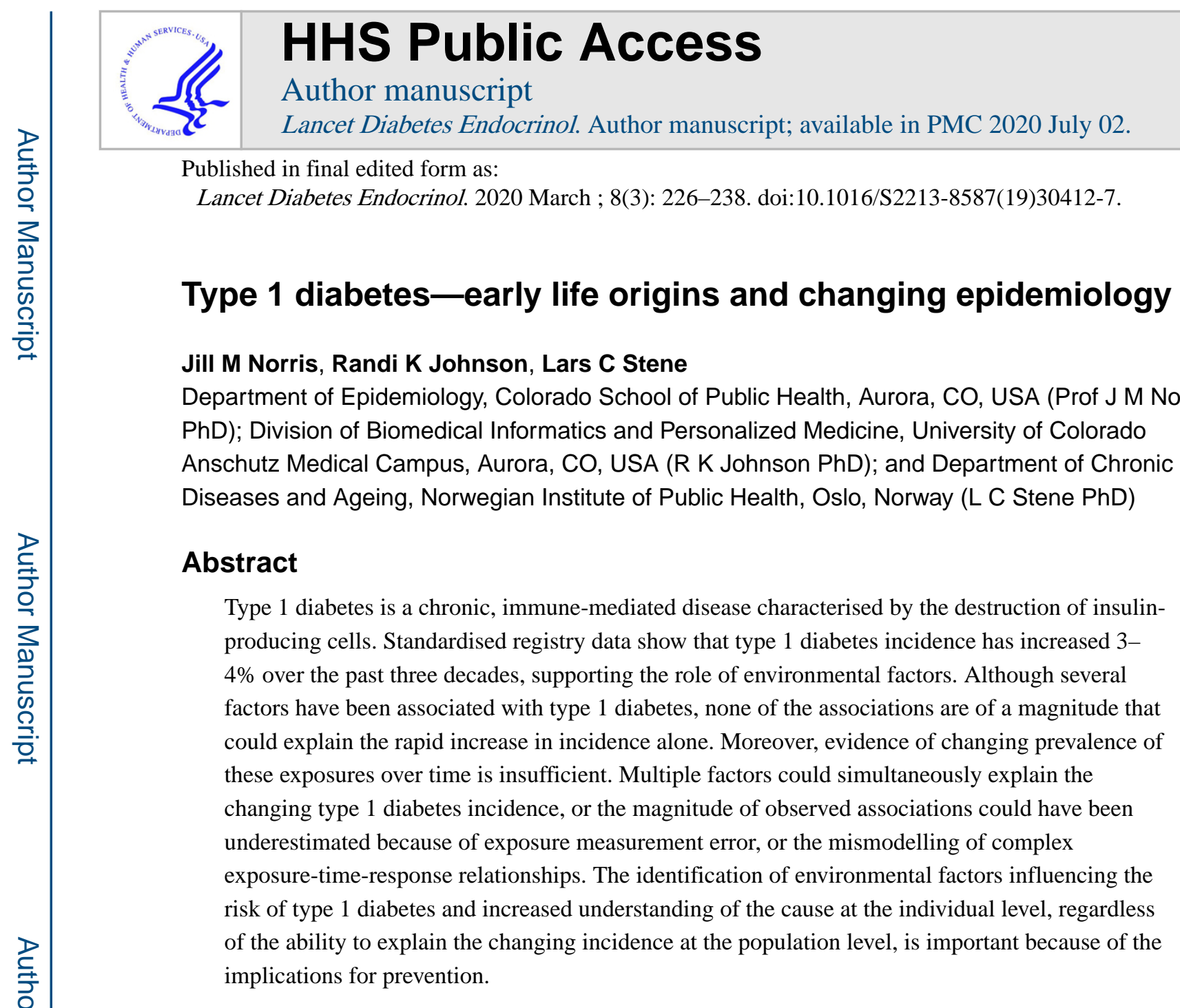

\title{
Introduction
}

Type 1 diabetes is a chronic, immune-mediated disease characterised by the destruction of insulin-producing $\beta$ cells in the pancreas. The development of $\beta$ cell autoantibodies is thought to be induced after a genetically-susceptible individual is exposed to a presumed environmental factor that triggers a loss of immune regulation. ${ }^{1}$ Destruction of $\beta$ cells leads to a decrease in insulin secretion, development of hyperglycaemia, and ultimately clinical type 1 diabetes. The asymptomatic phase in which multiple autoantibodies to $\beta$ cell antigens are detectable in serum is termed islet autoimmunity, and is highly predictive of type 1 diabetes. Seroconversion to islet autoimmunity occurs typically after 6 months of age and peaks between 12-24 months of age in children at increased risk for type 1 diabetes. ${ }^{2}$ Approximately $70 \%$ of children with multiple autoantibodies progress to type 1 diabetes within 10 years of seroconversion. ${ }^{3}$ Genetic variation in the HLA region accounts for a large

\footnotetext{
Correspondence to: Prof Jill M Norris, Department of Epidemiology, Colorado School of Public Health, Aurora, CO, USA, jill.norris@cuanschutz.edu.

Contributors

All authors contributed to the conception of the paper, literature search, drafting and final approval of the manuscript.

Declaration of interests

We declare no competing interests.

See Online for appendix
} 
proportion of the genetic risk associated with type 1 diabetes. The HLA haplotypes conferring the highest risk are HLA DR4-DQ8 and HLA DR3-DQ2. The risk is much higher for the heterozygote formed by these two haplotypes than for either of the homozygotes. In addition, over 50 genetic loci associated with type 1 diabetes risk have been identified, with effects ranging from moderate to small. ${ }^{4}$ We review epidemiological findings of putative environmental factors in the development of type 1 diabetes, with a focus on prospective studies evaluating risk factors, triggers of islet autoimmunity, and promoters of progression to type 1 diabetes. Most evidence for increasing type 1 diabetes incidence and prospective studies investigating exposures are limited to children younger than 20 years, therefore this review will be most relevant to childhood-onset type 1 diabetes. We also briefly review available data on time trends in relevant exposures.

\section{Trends in epidemiology}

The incidence of type 1 diabetes increases with age up to a peak around 10-14 years, but the disease can occur at any age. ${ }^{5}$ The incidence tends to be higher in boys than in girls in highincidence countries, with the opposite pattern seen in low-incidence countries. ${ }^{6}$ After puberty, males tend to have increasingly higher incidence of developing type 1 diabetes than females, even in low-incidence countries such as China. ${ }^{5}$ Most standardised long-term incidence data focus on children younger than 15 years, with incidence ranging from 1 to 3 per 100000 per year in China and other Asian and South American countries,, 5 around 1020 per 100000 in South European countries ${ }^{7}$ and in the USA, ${ }^{8}$ and 30-60 per 100000 in Scandinavia. ${ }^{7}$ Globally, the incidence of type 1 diabetes started to increase in the 1950 s with an average annual increase of $3-4 \%$ over the past three decades (figure 1). ${ }^{6,7,9}$ The relative increase tends to be highest in countries with low incidence. ${ }^{6,7}$ Early indications of a steeper relative increase among young children are no longer seen. ${ }^{7}$ In the long term, most countries have shown non-linear changes with periods of small or no increase such as in Norway from 2004 to 2012, and in Finland from 2006 to 2011. A small increase in incidence was seen in the USA during 2002-12.7,8

\section{Evidence for causal environmental factors}

The increasing incidence of type 1 diabetes in less than a generation supports the role of environmental factors. Although differences in incidence between countries might be partly due to genetic differences, the differences within countries of 1.5-3.0 fold and large differences between neighbouring countries with similar genetic composition are most likely due to yet unknown environmental factors. ${ }^{5,10,11}$ In the Environmental Determinants of Diabetes in the Young (TEDDY) study, ${ }^{2}$ Finnish centres reported an incidence of type 1 diabetes that was $78 \%$ higher than that in US centres, even after adjusting for HLA genotype, family history, and non-HLA loci. Again, non-genetic factors are the most likely explanation for this difference. The proportion of children with type 1 diabetes with the highest risk HLA genotype (DR4-DQ8 or DR3-DQ2) has declined over the past 2-4 decades, whereas the proportion with moderate risk HLA genotypes has increased. ${ }^{1,2}$ This finding is likely because of the penetrance of moderate risk HLA genotypes has increased over time due to increasing environmental exposures. ${ }^{12}$ 


\section{Timing and nature of environmental factors}

If a single factor were to explain the observed changes in incidence over the past few decades, it would have to be very strongly associated with the risk of type 1 diabetes. A factor that increased at a constant rate from nearly nonexistent in the population to nearly ubiquitous would have to confer a relative risk of five to explain an approximate $3 \%$ annual increase in incidence of type 1 diabetes (figure 2). Putative environmental factors changing less rapidly over time would have to be even more strongly associated with type 1 diabetes to explain the changing incidence trends. Additional simulations showed similar results for decreasing prevalence of a protective factor, and that even with three independent risk factors increasing in prevalence by $1 \%$ per year, the combined effect on the population incidence would be small, even if the relative risk conferred by all factors was five (appendix pp 3-5).

Identifying environmental factors associated with type 1 diabetes that influence the incidence of islet autoimmunity, or the rate of progression from islet autoimmunity to type 1 diabetes (hereafter termed progression to type 1 diabetes), can inform future preventive trials and searches for other environmental risk factors (figure 3). Suggestive evidence for the importance of environmental factors influencing progression comes from two observations. The first is the increasing progression to type 1 diabetes over time, but with no clear rise in islet autoimmunity incidence among genetically susceptible children in Germany. ${ }^{13}$ The second observation is the small geographical difference in prevalence of multiple autoantibody positivity among genetically susceptible children across Europe, by contrast with differing type 1 diabetes incidence rates. ${ }^{14}$ However, there was little or no difference in progression from multiple autoantibodies to type 1 diabetes between the high and low type 1 diabetes incidence centres in the TEDDY study. ${ }^{15}$ Paradoxically, the incidence of islet autoimmunity was only slightly higher in Finland than in the US centres in TEDDY, ${ }^{2}$ which leaves the question of the importance of islet autoimmunity triggers versus promoters of progression to type 1 diabetes largely unanswered. Investigating specific factors influencing islet autoimmunity or progression to type 1 diabetes is complex, and requires longitudinal studies as well as separate analysis for the two processes (figure 3). For practical reasons, such data have only been collected in genetically susceptible children, selected to have either moderate to high risk HLA genotypes or a family history of type 1 diabetes, or both. Examples of longitudinal birth cohort studies include: TEDDY, ${ }^{16}$ Diabetes Autoimmunity Study in the Young (DAISY),${ }^{17}$ Diabetes Prediction and Prevention (DIPP), ${ }^{18}$ MIDIA,${ }^{19}$ and the BABYDIAB study. ${ }^{20}$

\section{Environmental factors}

\section{Maternal and perinatal factors}

Higher maternal age at delivery, ${ }^{21}$ maternal pre-gestational and early gestational obesity, ${ }^{22,23}$ and caesarean section ${ }^{24}$ are factors that have become more common in the recent decades and which are also associated with higher type 1 diabetes risk in childhood. Findings from a meta-analysis have shown that the relative risks for type 1 diabetes are approximately 1.1 for maternal age of 35 years or more versus $25-30$ years, ${ }^{21} 1 \cdot 3-1 \cdot 4$ for maternal obesity, ${ }^{22,23}$ and 1.2 for caesarean section. ${ }^{24}$ Findings from more recent studies ${ }^{23,25}$ that have adjusted 
for maternal and confounding factors using a sibling-control design, ${ }^{26}$ have shown that the association of a caesarean section with type 1 diabetes is plausibly weaker and nonsignificant. These weak associations combined with a moderate rate of change in exposures (eg, caesarean sections increased by an average of 2.6\% annually from 1990 to 2014 among developed countries), ${ }^{27}$ suggest that these factors alone have little or no explanatory power.

Average birthweight has increased steadily in many populations, but began decreasing in the early 21 st century with some variation between countries. ${ }^{28}$ Higher birthweight has been associated with increased risk of type 1 diabetes in large studies, ${ }^{29}$ but the relative risk (approximately $1 \cdot 1$, comparing $>4 \mathrm{~kg}$ to $3-3.5 \mathrm{~kg}$ ) is also too weak to have any explanatory power.

\section{Infant growth and childhood obesity}

Childhood obesity and other measures of growth are risk factors thought to influence $\beta$-cell stress. In the USA, obesity prevalence among children aged 2-11 years increased during the 1990s and early 2000s but seems to have levelled off or slightly decreased since the mid-2000s, with similar trends in many other countries. ${ }^{30}$ Studies have shown that weight, ${ }^{31}$ weight gain in the first year of life (hazard ratio [HR] 1.2 per standard deviation increase), ${ }^{32}$ and early life $\mathrm{BMI}^{33,34}$ are all associated with increased risk of type 1 diabetes. A metaanalysis pooling studies that assess obesity or BMI before diagnosis of type 1 diabetes found positive associations between obesity and higher BMI during childhood and type 1 diabetes, with an estimated relative risk of 1.2 per standard deviation increase. ${ }^{35}$ A population-based nested case-control study from Denmark showed a similar association of BMI Z score at age 8 or 13 years, with later risk of developing type 1 diabetes. ${ }^{36}$ Genes associated with childhood BMI were associated with risk of type 1 diabetes in the general population, supporting the causality of this complex relationship which is otherwise difficult to assess. ${ }^{37}$ Prospective birth cohorts following-up individuals at high risk found conflicting associations between early life weight, height, and BMI on risk of islet autoimmunity. ${ }^{38-41}$ But there was a significant association in the TEDDY study, ${ }^{38}$ with a hazard ratio of approximately 1.2 per standard deviation increase in early childhood weight gain. In two other prospective cohorts, weight, height, and BMI at the time of islet autoimmunity were not associated with rate of progression to type 1 diabetes, although height growth velocity was associated with rate of progression to type 1 diabetes. ${ }^{40,41}$ Interpretation of the overall evidence is complicated by differences in exposure measures between studies. For example, studies have used attained height (height $\mathrm{Z}$ score) ${ }^{39}$ change in height (growth), ${ }^{32}$ height pattern over time, ${ }^{42}$ or height growth velocity. ${ }^{40}$ Nevertheless, most studies reporting significant associations find fairly small associations with the risk of type 1 diabetes. Similarly, lack of physical activity might trigger islet autoimmunity or accelerate progression to type 1 diabetes; however, there are no data available yet.

\section{Breastfeeding and introduction of cow's milk and solid foods}

Large cohort studies have not found any association between the duration of breastfeeding and risk of islet autoimmunity ${ }^{43-45}$ or type 1 diabetes. ${ }^{43,44,46,47}$ Moreover, the age at which cow's milk is introduced into the infant diet is not associated with risk of islet autoimmunity or type 1 diabetes. ${ }^{44-47}$ Similarly, a randomised trial found no effect of delaying the introduction of cow's milk into the infant diet on the risk of type 1 diabetes. ${ }^{48}$ Given that 
breastfeeding rates have increased since the 1970s, breastfeeding is unlikely to explain the increasing type 1 diabetes incidence. ${ }^{49,50}$ Cohort studies of timing of first exposure to solid foods and the risk for islet autoimmunity or type 1 diabetes are difficult to interpret because of heterogeneity in exposures and results, ${ }^{43-46}$ and insufficient data are available regarding population changes in complementary feeding over time.

However, prospective studies have shown that greater intake of cow's milk products in childhood is associated with increased risk of islet autoimmunity (HR of 1.05 for a $1 \mathrm{~g}$ increase in intake), ${ }^{46}$ and the progression from islet autoimmunity to type 1 diabetes (HR of 1.59 for a $16 \mathrm{~g}$ increase in intake).$^{52}$ Milk consumption has increased in China and Japan over time.$^{53,54}$ In the USA, overall consumption of milk products has increased between 1970 and 2014, largely because of increased cheese consumption, ${ }^{55}$ making it a potential candidate for explaining the increasing incidence of type 1 diabetes, although the association is small.

\section{Gluten and fibre intake}

Animal studies suggest that the incidence of autoimmune diabetes could be reduced by a diet that is free of gluten or rich in fibre, consumed by either pregnant dams or pups. Whereas in the Danish National Birth Cohort study, ${ }^{56}$ the amount of gluten in the maternal diet during pregnancy was borderline significantly associated with type 1 diabetes risk, this association was not found by the Norwegian Mother and Child Cohort study (MoBa) ${ }^{57}$ In the DAISY study, ${ }^{58}$ no association was found between gluten intake during childhood and incidence of islet autoimmunity or progression to type 1 diabetes. However, in the DIPP study, ${ }^{59}$ higher gluten and dietary fibre intake were strongly associated with incidence of islet autoimmunity and type 1 diabetes (adjusted HR of 3.4 per $10 \mathrm{~g}$ increase in gluten intake per day). Moreover, higher gluten intake at 18 months of age was associated with increased risk of type 1 diabetes in MoBa (adjusted HR of 1.5 per $10 \mathrm{~g}$ increase per day). ${ }^{57}$ The amount of dietary gluten is thought to have increased over time because of the added gluten in industrially baked breads, but there are scarce data on the quantitative effect. Overall, the potential role of dietary gluten and fibre in type 1 diabetes remains unclear, and more studies are needed.

\section{Vitamin D}

Given that both vitamin D status and type 1 diabetes incidence vary by latitude (ie, distance from the equator), vitamin $\mathrm{D}$ might be a protective factor for type 1 diabetes because it regulates the immune system and autoimmunity. Vitamin D intake during pregnancy was not associated with risk of islet autoimmunity in the offspring, and childhood vitamin D intake was not associated with risk of islet autoimmunity or progression to type 1 diabetes. ${ }^{60-62} \mathrm{~A}$ more relevant measure of vitamin D exposure could be circulating 25-hydroxyvitamin D $(25(\mathrm{OH}) \mathrm{D})$, which is determined by dietary intake and sun exposure of the skin, and reflects a person's vitamin D status. Numerous prospective studies have shown that there is no major association between serum 25(OH)D concentration in pregnancy ${ }^{63-66}$ and at birth, ${ }^{65-69}$ and the development of islet autoimmunity or type 1 diabetes in the child. In case-control studies of military cohorts, adult-onset type 1 diabetes cases had lower concentrations of 25(OH)D before diagnosis than did controls, ${ }^{70,71}$ yet the prospective studies DAISY and DIPP found 
no association between 25(OH)D concentration and islet autoimmunity development or progression to type 1 diabetes. ${ }^{62,72}$ In 2018, the TEDDY study found that higher plasma concentration of 25(OH)D in childhood was associated with a decreased risk of islet autoimmunity, although the effect size was small (HR 0.93 for $5 \mathrm{nmol}$ increase in 25(OH)D).

${ }^{73}$ Because population average $25(\mathrm{OH}) \mathrm{D}$ concentration remained stable over time in children aged 1-18 years in Sweden between 1982 and 2013, and in adolescents or adults in the USA between 1988 and $2010,{ }^{74,75}$ the increase in type 1 diabetes incidence is unlikely due to a decrease in $25(\mathrm{OH}) \mathrm{D}$ concentration in the population.

\section{Omega-3 fatty acids}

Given their anti-inflammatory properties, ${ }^{76-78}$ a deficiency of omega-3 fatty acids could predispose individuals to heightened inflammatory reactions, thus increasing the risk of type 1 diabetes. Alpha-linolenic acid is the principal omega-3 fatty acid in Western diets, and is found in green leaves, flax, canola, walnuts and soy. Other highly anti-inflammatory omega-3 fatty acids such as eicosapentaenoic acid (EPA), docosapentaenoic acid (DPA) and docosahexaenoic acid (DHA), are found in fatty fish and seal oil. Maternal intake of omega- 3 fatty acids ${ }^{74}$ and serum EPA and DHA concentration ${ }^{80}$ during pregnancy were not associated with risk of developing type 1 diabetes in the child.

The DIPP study found that higher serum DHA at 3 months of age was associated with decreased risk of developing islet autoimmunity. ${ }^{81}$ Moreover, the DAISY study showed that higher omega-3 fatty acid intake (primarily a-linolenic acid) and higher omega-3 fatty acid concentration (primarily DPA) in the erythrocyte membranes throughout childhood were associated with lower risk of islet autoimmunity, but were not associated with progression to type 1 diabetes. ${ }^{82-84}$ For omega-3 fatty acids to explain the increasing incidence of type 1 diabetes, intake and status would have to be declining in the population. Although there are no data on fatty acid status over time, omega-3 fatty acid intake does not appear to be decreasing. In Germany, children aged 0-18 years had slightly increased intake of EPA and DHA (as percentage of total fat intake) between 1985 and $2005 .{ }^{85}$ In the USA, women of reproductive age slightly increased their consumption of fish, therefore increasing EPA and DHA intake between 1999-2014. ${ }^{86,87}$

\section{Dietary sugars}

High-sugar diets increase insulin demand, which can lead to increased and persistent endoplasmic reticulum (ER) stress of the $\beta$ cell, causing apoptosis. ${ }^{88,89} \beta$-cell ER stress might promote the production of neo-autoantigens, resulting from post-translational modification of $\beta$-cell proteins, which could drive autoimmunity and progression to type 1 diabetes. ${ }^{90}$ The DAISY study showed that intake of dietary sugars is associated with progression to type 1 diabetes. In children with islet autoimmunity, a higher glycaemic index and an increased intake of total sugars was associated with a higher risk of progressing to type 1 diabetes. ${ }^{91,92}$ These intake variables were not associated with initial development of islet autoimmunity, suggesting that they are only related to acceleration of the later stage of type 1 diabetes. ${ }^{91,92}$ 
In the USA, calorie intake from added sugars consumed by children has significantly increased between 1977 and 2003. ${ }^{93}$ Similar trends have been observed in other countries, suggesting that sugar intake is a potential candidate for explaining the increase in type 1 diabetes incidence. ${ }^{94}$ There has been a decline in total sugar intake in numerous countries after 2003, which would be important to monitor in relation to the incidence of T1D and other diseases. ${ }^{93,94,95}$

\section{Infections}

\section{Enterovirus}

Viral infections have been candidate environmental factors in type 1 diabetes pathogenesis for decades. Mechanisms by which enteroviruses contribute to the destruction of pancreatic $\beta$ cells have been proposed. ${ }^{96}$ Early studies suggested a role of Coxsackievirus B4, but subsequent studies based on serum antibodies in newly diagnosed type 1 diabetes versus controls were inconsistent. ${ }^{97}$ Latest studies have searched for viruses using PCR on faecal, blood, or tissue samples, or in situ hybridisation in tissues. Many studies found small quantities of Enterovirus in patients with type 1 diabetes more frequently than in controls, but reverse causality cannot be ruled out. ${ }^{98}$ The DIPP study tested serum samples for neutralising antibodies to 41 Enterovirus serotypes before islet autoantibody positivity, and Coxsackievirus B1 was associated with higher risk of islet autoimmunity (odds ratio 1.5). ${ }^{99}$ Associations were only slightly significant and should be interpreted with caution because multiple testing correction was not done. However, a later cross-sectional study supported a potential role of Coxsackievirus B1 as a risk factor. ${ }^{100}$ Earlier studies of faecal Enterovirus shedding found no association with islet autoimmunity, ${ }^{101}$ but a 2017 study from Finland found an association between early Enterovirus shedding and islet autoimmunity months to years later. ${ }^{102}$ In 2019, the TEDDY study reported that long duration of faecal shedding of Enterovirus $B$ was associated with an approximately 3-4 times higher risk of islet autoimmunity, but there was no such association with type 1 diabetes. ${ }^{103}$ Enterovirus $B$ consists of several serotypes including Coxsackievirus 1-6 and many Echoviruses. The number of positive samples was not associated with islet autoimmunity for any of the 11 reported Enterovirus $B$ serotypes, except for a nominally significant association for Coxsackievirus B4. ${ }^{103}$ Although positive Enterovirus PCR in blood samples was more common before seroconversion for islet autoantibodies in children with type 1 diabetes, than in autoantibody negative controls in the DIPP study, ${ }^{104}$ there was no statistically significant difference in the MIDIA study. ${ }^{105}$ There was a suggestive difference between the first autoantibody positive sample in cases and corresponding sample in controls in MIDIA, ${ }^{105}$ however, as explained in figure 3, this difference could have been due to reverse causation. The DAISY study showed that presence of Enterovirus in serum predicted increased rate of progression from islet autoimmunity to type 1 diabetes. ${ }^{106}$

\section{Other viruses}

Other Picornaviruses including Parechoviruses ${ }^{107}$ and Saffold virus, ${ }^{108}$ have not been consistently associated with islet autoimmunity or type 1 diabetes. Serological response to influenza A was not associated with risk of islet autoimmunity. ${ }^{109}$ However, a large registry- 
based study from Norway suggested that severe influenza, during the 2009 H1N1 influenza

A pandemic, was associated with increased risk of type 1 diabetes. ${ }^{110}$

\section{Metagenomic sequencing for virus detection}

The possibility to detect previously unknown viruses makes metagenomics an attractive approach, but technical challenges remain. ${ }^{111} \mathrm{~A}$ few small to moderately-sized studies reported no significant association between frequency of any viruses and islet autoimmunity, but these studies remain difficult to interpret because of nonstandardised analytical techniques. ${ }^{111-114}$ The TEDDY study reported prospective virome data based on metagenomic sequencing of faecal samples. Among the 12 most frequently detected viruses (apart from enterovirus), higher frequency of Adenovirus $\mathrm{C}$ was associated with a lower risk of islet autoimmunity in children aged 3-6 years. This novel association needs to be strengthened in further studies. ${ }^{103}$

\section{Respiratory infections}

Increased frequency of symptomatic respiratory infections in early childhood was first reported to be associated with risk of islet autoimmunity ${ }^{115}$ and type 1 diabetes ${ }^{116}$ in 2011. This finding was surprising as most focus had been on gastrointestinal infections, but suggests that general viral infections non-specifically could predispose to initiation or progression of islet autoimmunity. Initial observations were later supported by three independent studies, ${ }^{117-119}$ but the results were not supported by the MoBa study for type 1 diabetes. ${ }^{120}$

\section{Maternal virus infections}

Maternal infection during pregnancy has been postulated as a risk factor for childhood onset type 1 diabetes, but the consistency across studies is difficult to interpret because of varying study designs. ${ }^{121}$ The MoBa study found that frequency of infections reported by the mother during pregnancy was not associated with risk of type 1 diabetes in children. ${ }^{120}$

In addition to the inconsistent evidence for a role of viruses in the cause of type 1 diabetes, there is little evidence that potentially diabetogenic viral infections are becoming more frequent in pregnant women or in children, and therefore could explain time trends in type 1 diabetes.

\section{The hygiene hypothesis and proxies of microbial exposures}

Early exposure to microbial products and infections is hypothesised to stimulate the immune system and lower risk of allergies and autoimmune diseases. ${ }^{122}$ It has also been suggested that increased use of vaccines and antibiotics, and hence fewer natural infections, contributed to increased risk. The hygiene hypothesis was originally formulated on the basis of atopic disorders in first-born and later-born children. A pooled analysis of more than 30 studies, showed a slightly lower risk of type 1 diabetes in second or later-born children compared with first-born (adjusted pooled odds ratio 0.90, 95\% CI 0.83-0.98), but with marked heterogeneity between studies. ${ }^{123}$ Proxy variables of microbial exposure such as household crowding, attending day care, and population density can capture exposure that is 
difficult to measure, but they are also imprecise and confounded. Existing studies of these factors show no clear association with type 1 diabetes. Data on exposure to farm environment or animals are scarce and do not suggest any association with type 1 diabetes. 124,125

\section{Helminths}

Decreased exposure to parasitic helminths, such as Enterobius vermicularis (pinworm), was suggested to explain the increase in immune-mediated diseases. Although this hypothesis cannot be supported by existing data, circumstantial counterevidence includes the observation that pinworm is still very common, and there is no association between antiworm medication and risk of type 1 diabetes. ${ }^{126,127}$

\section{Antibiotics}

Although use of antibiotics is an indicator of infection, they might also influence immunemediated diseases by infection-independent mechanisms such as induction of gut dysbiosis. Although subtle changes in gut microbiota can persist particularly after broad spectrum antibiotics, most changes in the gut microbiome after common antibiotics are largely reversible within 3-4 weeks. Several large studies have not found any consistent association between use of antibiotics in childhood and the risk of type 1 diabetes, ${ }^{120,128-131}$ or islet autoimmunity. ${ }^{125,132}$ Use of antibiotics during pregnancy is also not associated with type 1 diabetes in children. ${ }^{120,128,133}$

\section{Vaccinations}

A systematic review on childhood vaccines and type 1 diabetes based on 23 studies and 16 different vaccines concluded that there was no overall evidence for any association between common childhood vaccines and risk of type 1 diabetes. ${ }^{134}$ Similarly, a comprehensive analysis of children at high risk of type 1 diabetes found no association with childhood vaccinations and islet autoimmunity, ${ }^{135}$ consistent with previous studies. Rotavirus vaccination introduced in many countries in the 2000s, was not significantly associated with type 1 diabetes in children in Finland, ${ }^{136}$ but a suggestive lower incidence was seen in vaccinees in Australia ${ }^{137}$ and USA. ${ }^{138}$ Follow-up of participants from a randomised trial of RotaTeq in Finland did not find any significant difference in incidence of type 1 diabetes after $12-14$ years. ${ }^{139}$ Overall, vaccines are unlikely to explain the changing epidemiology of type 1 diabetes, but further studies of rotavirus vaccines are warranted.

\section{The polio model}

The polio model has been suggested by analogy with poliomyelitis, where a proportion $(<1 \%)$ of those infected with the causative virus (poliovirus) get the clinical disease (poliomyelitis). Early infection with poliovirus in the presence of maternal antibodies might be protective of poliomyelitis. Declining titres of maternal Enterovirus antibodies ${ }^{140}$ in Finland and Sweden during 1983-2001 and higher seroprevalence of Enterovirus in countries with low incidence of type 1 diabetes ${ }^{141}$ provides indirect evidence in support for such a scenario. Individual level evidence is needed to draw firmer conclusions. The reduced 
incidence of type 1 diabetes in children following vaccination of pregnant women would possibly provide additional evidence in the future.

The hygiene hypothesis might explain long-term trends in type 1 diabetes epidemiology. However, the evidence for human type 1 diabetes is indirect, with no evidence that any of the proxies studied are related to the incidence of this disease.

\section{Toxins}

Environmental chemicals have been suggested to influence type 1 diabetes by various mechanisms, but there are few high quality studies of human type 1 diabetes. ${ }^{142} \mathrm{~A}$ few studies have found suggestive evidence for an association between air pollution and risk of type 1 diabetes, but there are methodological difficulties with exposure measurements. Overall, there seem to be no consistent association between environmental toxins and type 1 diabetes, or islet autoimmunity. ${ }^{142,143}$ Although many toxins have been introduced into the environment, many have been banned resulting in decreasing exposure trends. ${ }^{144}$ Air pollution is highest in areas with low incidence of type 1 diabetes and has decreased over the past decades in high-income countries. ${ }^{145}$ Environmental toxins are therefore unlikely to explain the time trends in type 1 diabetes incidence.

Smoking during pregnancy has become less prevalent over the past decades in many countries. Maternal smoking has surprisingly been associated with lower risk of type 1 diabetes in children in several studies, with a relative risk of 0.7. ${ }^{146,147}$ However, even if the time trends and direction of association are consistent, the association is probably too weak to explain time trends in type 1 diabetes incidence.

\section{Endogenous factors reflecting environmental exposures}

Changing trends in type 1 diabetes incidence are most likely due to exogenous exposures. Although these exposures remain unknown, reliable measurement of non-genetic factors (eg, diet, infection, and toxins) is difficult. Rapid technological development has enabled the use of high-throughput multiomics datasets in epidemiological studies, which could help to improve the measurement of non-genetic exposures and understanding of type 1 diabetes pathophysiology. For example, the gut microbiota can now be comprehensively assessed and is suggested to influence immunity and a range of physiological processes relevant to diseases such as type 1 diabetes. Several environmental factors that we have reviewed, including caesarean sections, breastfeeding, and the time of solid food introduction, have proposed mechanisms of action by modulation of the gut microbiome. The largest prospective study of the gut microbiome in type 1 diabetes patients showed that breastfeeding is the most important determinant of microbiome structure in early life. ${ }^{148,149}$ However, there was a small difference between islet autoimmunity and type 1 diabetes cases versus controls in terms of microbiome diversity, composition, and stability, ${ }^{148}$ with only slight differences in microbiome metagenomic sequences. ${ }^{149}$ Prospective investigation of other molecular signatures (metabolomics, proteomics) in type 1 diabetes and its candidate environmental risk factors are ongoing, and similarly show some, but inconclusive, promise. Future application of integrative genomics could improve our ability to reliably assess 
complete exposure history (the exposome), ${ }^{150}$ and provide insight into biological mechanisms of disease pathogenesis, but many challenges remain to be addressed.

\section{Future studies}

We are currently unable to explain the changing type 1 diabetes incidence trends. Identification of environmental factors influencing type 1 diabetes risk and improving understanding of the cause at the individual level is important because of potential implications for prevention, regardless of the ability to explain changing incidence at population level. We could be looking at the wrong factors altogether, but various complexities might prevent the identification of consistent associations between environmental factors and risk of type 1 diabetes. Here, we briefly discuss factors that can complicate the identification of causal environmental factors in type 1 diabetes.

\section{Complexities}

As for many multifactorial diseases, risk factors for type 1 diabetes are most likely to be contributory and neither necessary nor sufficient for development of the disease. However, it is possible that one or a few factors are necessary and ubiquitous. Such hypothetical factors will be difficult to identify in observational studies but could have tremendous potential for prevention.

Compared with many other complex diseases such as type 2 diabetes or asthma, type 1 diabetes could be viewed as a homogeneous disease. Known monogenic forms of diabetes should be excluded from the study population, but type 1 diabetes could possibly consist of disease subgroups. Exact definition of sub-groups is difficult, but if different individuals with the same phenotype (type 1 diabetes) have resulted from different combinations of causative factors (both genetic and non-genetic), identification of the causes will obviously be more difficult.

The observed incidence trends are most likely explained by multiple factors, possibly a combination of decreased exposure to factors lowering the risk and increased exposure to factors increasing the risk. Expanding the simulated scenarios in figure 2 to a combination of three factors gave similar overall results for exposure factors increasing by $1 \%$ per year in prevalence (appendix p 4). This result suggests that the true number of factors involved might be larger. In a situation with numerous explanatory factors, identification of any one of them is more difficult because of weak individual effects in any population, and the effect of each might differ within populations over time.

As discussed above and in figure 3, different environmental factors might affect different stages of the disease process.

Even with only one exposure being studied, the multiple possibilities regarding exposure trajectories, induction times, dose-response, and sensitive or critical windows of exposure complicates the identification of associations and interpretation of data. Appropriate modelling is necessary to correctly link exposures to disease risk, which could be 
particularly important during periods of non-linear changes in incidence when attempting to explain time trends using individual-level data.

Depending on the pattern of exposure and the underlying dose-time-disease relationship, causal exposures might result in changing time trends affecting whole birth cohorts, or result in changes over calendar time that affect several different birth cohorts, or a mix of the two. Most type 1 diabetes incidence data are presented according to calendar period (figure 1). If for instance an exposure in early life, such as vaccination, is abruptly introduced, patterns will be most easily detectable according to birth cohort analyses. In practice, these two patterns are difficult to disentangle.

There is always some error in exposure measurements. These errors include not only imprecision or bias in laboratory assays, but also day-to-day variability in exposures not captured by a single or few measurements, stability of biomarkers during sample handling, and numerous other factors. Differential measurement errors can give biased results, and non-differential measurement errors (random noise) create bias of results towards no association.

Interaction means that the magnitude or presence of an effect differs depending on the presence or level of another factor. Both gene-environment and environment-environment interactions might be involved in the cause of type 1 diabetes, which could imply that effects or associations are detectable only in subgroups. The complexity of these interactions entails the need for measurement of all factors, correct statistical modelling, and much larger sample sizes for robust statistical inference. Most genetic susceptibility loci for type 1 diabetes include genes involved in immunity, particularly HLA, therefore genotypes could influence response to infection and hence risk of type 1 diabetes. We are not aware of any studies that have shown that the association between a virus and type 1 diabetes varies by genotype. Nevertheless, several examples of gene-environment interactions have been reported. In the MoBa study, ${ }^{66}$ higher cord blood 25(OH)D was associated with decreased risk of type 1 diabetes only in children who were homozygous for the $\mathrm{G}$ allele at the vitamin D receptor gene $(V D R)$ variant rs 11568820 . The TEDDY study ${ }^{73}$ found that higher plasma 25(OH)D concentration in childhood was associated with a decreased risk of islet autoimmunity only in children carrying minor alleles at rs7975232 in the $V D R$ gene. These results suggest that the underlying susceptibility for islet autoimmunity and type 1 diabetes might be related to the ability to adequately use vitamin $\mathrm{D}$, as $25(\mathrm{OH}) \mathrm{D}$ is converted into $1,25(\mathrm{OH}) 2 \mathrm{D}$, which binds with the $V D R$ gene to regulate gene expression.

In the DAISY study, ${ }^{83}$ an inverse association between a-linolenic acid intake and islet autoimmunity was seen only in individuals with minor alleles at the fatty acid desaturase gene (FADS) variants. As a-linolenic acid could be a precursor for EPA, DPA, and DHA using desaturation enzymes encoded by $F A D S$ genes, the observed susceptibility might be related to the ability to convert $a$-linolenic acid to the more anti-inflammatory fatty acids. When searching for interactions, we realise that the number of potential interactions, even when restricted to two-way interactions, quickly becomes overwhelming. The large number of interactions results in multiplicity problems that need to be balanced against the ability to detect relevant associations. 
In addition to the interaction example above, there are other kinds of multiplicity that could affect our ability to investigate this question. For example, when we test many different factors one-by-one there is risk of multiple testing and false positives, where many nominally significant associations are expected under the null hypothesis. When predicting outcomes with flexible modelling or pattern identification algorithms using numerous predictors simultaneously, we are vulnerable to overfitting. Although increasing the number of predictors we measure will increase the chance of including relevant factors, the downside is the so called curse of dimensionality, which refers to a situation in which there are more predictors (exposure variables) than study participants and reliable prediction becomes difficult. ${ }^{151}$ To account for dimensionality, we would need to assemble longitudinal cohort studies with nearly prohibitive sample sizes. The need for detailed data collection and flexible modelling should be balanced against the risk of false positive findings due to multiplicity.

Epidemiological or statistical methods to explain long-term trends have not been well developed. Moreover, these methods require more detailed datasets with standardised measurements of exposure and type 1 diabetes incidence data over numerous years, sometimes decades. Existing high-risk birth cohorts do not have enough data for this standardisation and patterns in these cohorts might not be representative of the general population.

\section{Ways forward}

We recommend that the way to obtain robust results from prospective studies is to combine well-planned studies with good, a priori designed and transparent, standardised protocols, and a documented analysis pipeline from collection of raw data to main analysis. An appealing, but complex approach is joint modelling, especially with longitudinal exposure and time-to-event data. This approach can be done in numerous ways according to the hypothesised exposure-time-response relationship. Moreover, in terms of interactions or subgroup analyses, rather than the exposome-wide association study, which would encounter multiplicity problems with many false positives, it might be better to identify replicable marginal associations first, and limit searches for interactions to those involving plausible factors producing a marginal signal. Identifying time trends in exposure prevalence consistent with time trends in type 1 diabetes incidence could be the first step to show that environmental factors might be influencing changing incidence. However, this approach is equivalent to an ecological study design which is more prone to bias than individual-level studies. Instead, standardised measures of exposure variables are needed at individual-level, when type 1 diabetes incidence is changing markedly in population-based studies. In such datasets, calendar year (or year of birth) will be statistically associated with type 1 diabetes incidence. Regression modelling can be used to investigate whether all or part of the association of calendar year with type 1 diabetes incidence is accounted for by specific environmental exposures. We are unaware of applications of this methodology, except in our simulated data (figure 2). 


\section{Conclusion}

Several factors have been associated with type 1 diabetes but none of the associations appears to be of a magnitude that could explain the rapid increase in type 1 diabetes incidence. Multiple factors simultaneously could explain the changing type 1 diabetes incidence, but we might have missed the most relevant factor altogether. Alternatively, the magnitude of observed associations could have been underestimated because of complicating factors such as exposure measurement error, or mismodeling of complex timedose-response relationships. Searching for environmental factors influencing type 1 diabetes risk at the individual level is of interest because of the potential implications for prevention.

\section{Supplementary Material}

Refer to Web version on PubMed Central for supplementary material.

\section{Acknowledgments}

JMN and RKJ were funded in part by National Institutes of Health-R01-DK 104351, DK32493 and R21-AI 142483. LCS was funded in part by the Research Council of Norway and the Norwegian Institute of Public Health.

\section{References}

1. Atkinson MA, Eisenbarth GS, Michels AW. Type 1 diabetes. Lancet 2014; 383: 69-82. [PubMed: 23890997]

2. Krischer JP, Lynch KF, Lernmark A, et al. Genetic and environmental interactions modify the risk of diabetes-related autoimmunity by 6 years of age: the TEDDY study. Diabetes Care 2017; 40: 1194 202. [PubMed: 28646072]

3. Ziegler AG, Rewers M, Simell O, et al. Seroconversion to multiple islet autoantibodies and risk of progression to diabetes in children. JAMA 2013; 309: 2473-79. [PubMed: 23780460]

4. Robertson CC, Rich SS. Genetics of type 1 diabetes. Curr Opin Genet Dev 2018; 50: 7-16. [PubMed: 29453110]

5. Weng J, Zhou Z, Guo L, et al. Incidence of type 1 diabetes in China, 2010-13: population based study. BMJ 2018; 360: j5295. [PubMed: 29298776]

6. Diamond project group. Incidence and trends of childhoodtype 1 diabetes worldwide 1990-1999. Diabet Med 2006; 23: 857-66. [PubMed: 16911623]

7. Patterson CC, Harjutsalo V, Rosenbauer J, et al. Trends and cyclical variation in the incidence of childhood type 1 diabetesin 26 European centres in the 25 year period 1989-2013: a multicentre prospective registration study. Diabetologia 2019; 62: 408-17. [PubMed: 30483858]

8. Mayer-Davis EJ, Lawrence JM, Dabelea D, et al. Incidence trends of type 1 and type 2 diabetes among youths, 2002-2012. N Engl J Med 2017; 376: 1419-29. [PubMed: 28402773]

9. Gale EA. The rise of childhood type 1 diabetes in the 20th century. Diabetes 2002; 51: 3353-61. [PubMed: 12453886]

10. Kondrashova A, Reunanen A, Romanov A, et al. A six-fold gradient in the incidence of type 1 diabetes at the eastern border of Finland. Ann Med 2005; 37: 67-72. [PubMed: 15902849]

11. Backman VM, Thorsson AV, Fasquel A, et al. HLA class II alleles and haplotypes in Icelandic type I diabetic patients: comparison of Icelandic and Norwegian populations. Diabetologia 2002;45: 452-58. [PubMed: 11914753]

12. Fourlanos S, Varney MD, Tait BD, et al. The rising incidence of type 1 diabetes is accounted for by cases with lower-risk human leukocyte antigen genotypes. Diabetes Care 2008; 31: 1546-49. [PubMed: 18487476] 
13. Ziegler AG, Pflueger M, Winkler C, et al. Accelerated progression from islet autoimmunity to diabetes is causing the escalating incidence of type 1 diabetes in young children. $\mathrm{J}$ Autoimmun 2011; 37: 3-7. [PubMed: 21376535]

14. Williams AJ, Bingley PJ, Moore WP, Gale EA, et al. Islet autoantibodies, nationality and gender: a multinational screening study in first-degree relatives of patients with type I diabetes. Diabetologia 2002; 45: 217-23. [PubMed: 11935153]

15. Krischer JP, Liu X, Lernmark A, et al. The influence of type 1 diabetes genetic susceptibility regions, age, sex, and family history on the progression from multiple autoantibodies to type 1 diabetes: a TEDDY study report. Diabetes 2017; 66: 3122-29. [PubMed: 28903990]

16. TEDDY Study Group. The environmental determinants of diabetes in the young (TEDDY) study. Ann N Y Acad Sci 2008; 1150: 1-13.

17. Barker JM, Barriga KJ, Yu L, et al. Prediction of autoantibody positivity and progression to type 1 diabetes: diabetes autoimmunity study in the young (DAISY). J Clin Endocrinol Metab 2004;89: 3896-902. [PubMed: 15292324]

18. Kimpimäki T, Kulmala P, Savola K, et al. Natural history of beta-cell autoimmunity in young children with increased genetic susceptibility to type 1 diabetes recruited from the general population. J Clin Endocrinol Metab 2002; 87: 4572-79. [PubMed: 12364437]

19. Stene LC, Wits $\varnothing$ E, Torjesen PA, et al. Islet autoantibody development during follow-up of highrisk children from the general Norwegian population from three months of age: design and early results from the MIDIA study. J Autoimmun 2007; 29: 44-51. [PubMed: 17560077]

20. Ziegler AG, Hummel M, Schenker M, Bonifacio E. Autoantibody appearance and risk for development of childhood diabetes in offspring of parents with type 1 diabetes: the 2-year analysis of the German BABYDIAB study. Diabetes 1999; 48: 460-68. [PubMed: 10078544]

21. Cardwell CR, Stene LC, Joner G, et al. Maternal age at birth and childhood type 1 diabetes: a pooled analysis of 30 observational studies. Diabetes 2010; 59: 486-94. [PubMed: 19875616]

22. Magnus MC, Olsen SF, Granström C, et al. Paternal and maternal obesity but not gestational weight gain is associated withtype 1 diabetes. Int J Epidemiol 2018; 47: 417-26. [PubMed: 29415279]

23. Waernbaum I, Dahlquist G, Lind T. Perinatal risk factors for type 1 diabetes revisited: a population-based register study. Diabetologia 2019; 62: 1173-84. [PubMed: 31041471]

24. Cardwell CR, Stene LC, Joner G, et al. Caesarean section is associated with an increased risk of childhood-onset type 1 diabetes mellitus: a meta-analysis of observational studies. Diabetologia 2008; 51: 726-35. [PubMed: 18292986]

25. Clausen TD, Bergholt T, Eriksson F, Rasmussen S, Keiding N, Lokkegaard EC. Prelabor cesarean section and risk of childhood type 1 diabetes: a nationwide register-based cohort study. Epidemiology 2016; 27: 547-55. [PubMed: 27031040]

26. Khashan AS, Kenny LC, Lundholm C, Kearney PM, Gong T, Almqvist C. Mode of obstetrical delivery and type 1 diabetes: a sibling design study. Pediatrics 2014; 134: e806-13. [PubMed: 25092933]

27. Betran AP, Ye J, Moller AB, Zhang J, Gulmezoglu AM, Torloni MR. The increasing trend in caesarean section rates: global, regional and national estimates: 1990-2014. PLoS One 2016; 11: e0148343. [PubMed: 26849801]

28. Donahue SM, Kleinman KP, Gillman MW, Oken E. Trends in birthweight and gestational length among singleton term births in the United States: 1990-2005. Obstet Gynecol 2010; 115: 357-64. [PubMed: 20093911]

29. Cardwell CR, Stene LC, Joner G, et al. Birthweight and the riskof childhood-onset type 1 diabetes: a meta-analysis of observational studies using individual patient data. Diabetologia 2010; 53: 64151. [PubMed: 20063147]

30. Ogden CL, Carroll MD, Lawman HG, et al. Trends in obesity prevalence among children and adolescents in the United States, 1988-1994 through 2013-2014. JAMA 2016; 315: 2292-99. [PubMed: 27272581]

31. Hypponen E, Virtanen SM, Kenward MG, Knip M, Akerblom H, Childhood Diabetes in Finland Study Group. Obesity, increased linear growth, and risk of type 1 diabetes in children. Diabetes Care 2000; 23: 1755. [PubMed: 11128347] 
32. Magnus MC, Olsen SF, Granström C, et al. Infant growth and risk of childhood-onset type 1 diabetes in children from 2 scandinavian birth cohorts. JAMA Pediatr 2015; 169: e153759. [PubMed: 26642117]

33. Svensson J, Carstensen B, Mortensen HB, Borch-Johnsen K. Growth in the first year of life and the risk of type 1 diabetes in a Danish population. Paediatr Perinat Epidemiol 2007; 21: 44-48. [PubMed: 17239178]

34. Substudy EURODIAB 2 Study Group. Rapid early growth is associated with increased risk of childhood type 1 diabetes in various European populations. Diabetes Care 2002; 25: 1755-60. [PubMed: 12351473]

35. Verbeeten KC, Elks CE, Daneman D, Ong KK. Association between childhood obesity and subsequent type 1 diabetes: a systematic review and meta-analysis. Diabet Med 2011; 28: 10-18. [PubMed: 21166841]

36. Antvorskov JC, Aunsholt L, Buschard K, et al. Childhood body mass index in relation to subsequent risk of type 1 diabetes-a Danish cohort study. Pediatr Diabetes 2018; 19: 265-70. [PubMed: 28940941]

37. Censin JC, Nowak C, Cooper N, Bergsten P, Todd JA, Fall T. Childhood adiposity and risk of type 1 diabetes: a Mendelian randomization study. PLoS medicine 2017; 14: e1002362. [PubMed: 28763444]

38. Elding Larsson H, Vehik K, Haller MJ, et al. Growth and riskfor islet autoimmunity and progression to type 1 diabetes in early childhood: the environmental determinants of diabetes in the young study. Diabetes 2016; 65: 1988-95. [PubMed: 26993064]

39. Couper JJ, Beresford S, Hirte C, et al. Weight gain in early life predicts risk of islet autoimmunity in children with first-degree relative with type 1 diabetes. Diabetes Care 2009; 32: 94-99. [PubMed: 18835948]

40. Lamb MM, Yin X, Zerbe GO, et al. Height growth velocity, islet autoimmunity and type 1 diabetes development: the diabetes autoimmunity study in the young. Diabetologia 2009; 52: 2064-71. [PubMed: 19547949]

41. Winkler C, Raab J, Grallert H, Ziegler AG. Lack of association of type 2 diabetes susceptibility genotypes and body weight on the development of islet autoimmunity and type 1 diabetes. PLoS One 2012; 7: e35410. [PubMed: 22558147]

42. Yassouridis C, Leisch F, Winkler C, Ziegler AG, Beyerlein A. Associations of growth patterns and islet autoimmunity in children with increased risk for type 1 diabetes: a functional analysis approach. Pediatr Diabetes 2017; 18: 103-10. [PubMed: 26890567]

43. Chmiel R, Beyerlein A, Knopff A, Hummel S, Ziegler AG, Winkler C. Early infant feeding and risk of developing islet autoimmunity and type 1 diabetes. Acta Diabetologica 2015; 52: 621-24. [PubMed: 25038720]

44. Hakola L, Takkinen HM, Niinisto S, et al. Infant feeding in relation to the risk of advanced islet autoimmunity and type 1 diabetes in children with increased genetic susceptibility: a cohort study. Am J Epidemiol 2018; 187: 34-44. [PubMed: 29309515]

45. Uusitalo U, Lee HS, Andren Aronsson C, et al. Early infant diet and islet autoimmunity in the TEDDY study. Diabetes Care 2018; 41: 522-30. [PubMed: 29343517]

46. Frederiksen B, Kroehl M, Lamb MM, et al. Infant exposures and development of type 1 diabetes mellitus: the diabetes autoimmunity study in the young (DAISY). JAMA Pediatr 2013; 167: 80815. [PubMed: 23836309]

47. Lund-Blix NA, Dydensborg Sander S, Størdal K, et al. Infant feeding and risk of type 1 diabetes in two large Scandinavian birth cohorts. Diabetes Care 2017; 40: 920-27. [PubMed: 28487451]

48. Writing Group for the TRIGR Study Group, Knip M, Akerblom HK, et al. Effect of hydrolyzed infant formula $v s$ conventional formula on risk of type 1 diabetes: the TRIGR randomized clinical trial. JAMA 2018; 319: 38-48. [PubMed: 29297078]

49. McGuire S US Dept of Health and Human Services. The surgeon general's call to action to support breastfeeding. U.S. dept. of health and human services, office of the surgeon general. 2011. Adv Nutr 2011; 2: 523-24. [PubMed: 22332095] 
50. Simpson DA, Quigley MA, Kurinczuk JJ, Carson C. Twenty-five-year trends in breastfeeding initiation: the effects of sociodemographic changes in Great Britain, 1985-2010. PLoS One 2019; 14: e0210838. [PubMed: 30653579]

51. Virtanen SM, Nevalainen J, Kronberg-Kippila C, et al. Food consumption and advanced $\beta$ cell autoimmunity in young children with HLA-conferred susceptibility to type 1 diabetes: a nested case-control design. Am J Clin Nutr 2012; 95: 471-78. [PubMed: 22237062]

52. Lamb MM, Miller M, Seifert JA, et al. The effect of childhood cow's milk intake and HLA-DR genotype on risk of islet autoimmunity and type 1 diabetes: the diabetes autoimmunity study in the young. Pediatr Diabetes 2015; 16: 31-38. [PubMed: 24444005]

53. Bai Z, Lee MRF, Ma L, et al. Global environmental costs of China's thirst for milk. Glob Change Biol 2018; 24: 2198-211.

54. Murakami K, Livingstone MBE, Sasaki S. Thirteen-year trends in dietary patterns among Japanese adults in the national health and nutrition survey 2003-2015: continuous westernization of the Japanese diet. Nutrients 2018; 10: e994. [PubMed: 30061492]

55. Bentley JUS trends in food availability and a dietary assessment of loss-adjusted food availability, 1970-2014. Economic Information Bulletin 2017; 253947.

56. Antvorskov JC, Halldorsson TI, Josefsen K, et al. Association between maternal gluten intake and type 1 diabetes in offspring: national prospective cohort study in Denmark. BMJ 2018;362: k3547. [PubMed: 30232082]

57. Lund-Blix NA, Tapia G, Mårild K, et al. Maternal and child gluten intake and association with type 1 diabetes: the Norwegian mother and child cohort study. PLoS Med (in press).

58. Lund-Blix NA, Dong F, Marild K, et al. Gluten intake and risk of islet autoimmunity and progression to type 1 diabetes in children at increased risk of the disease: the diabetes autoimmunity study in the young (DAISY). Diabetes Care 2019; 42: 789-96. [PubMed: 30796108]

59. Hakola L, Miettinen ME, Syrjala E, et al. Association of cereal, gluten, and dietary fiber intake with islet autoimmunity and type 1 diabetes. JAMA Pediatr 2019; 173: 953-60.

60. Silvis K, Aronsson CA, Liu X, et al. Maternal dietary supplement use and development of islet autoimmunity in the offspring: TEDDY study. Pediatr Diabetes 2019; 20: 86-92. [PubMed: 30411443]

61. Marjamaki L, Niinisto S, Kenward MG, et al. Maternal intake of vitamin D during pregnancy and risk of advanced $\beta$ cell autoimmunity and type 1 diabetes in offspring. Diabetologia 2010; 53: 1599-607. [PubMed: 20369220]

62. Simpson M, Brady H, Yin X, et al. No association of vitamin D intake or 25-hydroxyvitamin D levels in childhood with risk of islet autoimmunity and type 1 diabetes: the diabetes autoimmunity study in the young (DAISY). Diabetologia 2011; 54: 2779-88. [PubMed: 21858504]

63. Miettinen ME, Reinert L, Kinnunen L, et al. Serum 25-hydroxyvitamin D level during early pregnancy and type 1 diabetes risk in the offspring. Diabetologia 2012; 55: 1291-94. [PubMed: 22270224]

64. Sørensen IM, Joner G, Jenum PA, Eskild A, Torjesen PA, Stene LC. Maternal serum levels of 25hydroxy-vitamin D during pregnancy and risk of type 1 diabetes in the offspring. Diabetes 2012;61: 175-78. [PubMed: 22124461]

65. Thorsen SU, Mårild K, Olsen SF, et al. Lack of association between maternal or neonatal vitamin d status and risk of childhoodtype 1 diabetes: a Scandinavian case-cohort study. Am J Epidemiol 2018; 187: 1174-81. [PubMed: 29186303]

66. Tapia G, Mårild K, Dahl SR, et al. Maternal and newborn vitamin D-binding protein, vitamin D levels, vitamin D receptor genotype, and childhood type 1 diabetes. Diabetes Care 2019;42: 55359. [PubMed: 30692241]

67. Cadario F, Savastio S, Pagliardini V, et al. Vitamin D levels at birth and risk of type 1 diabetes in childhood: a case-control study. Acta Diabetologica 2015; 52: 1077-81. [PubMed: 26018939]

68. Jacobsen R, Thorsen SU, Cohen AS, et al. Neonatal vitamin D status is not associated with later risk of type 1 diabetes: results from two large Danish population-based studies. Diabetologia 2016; 59: 1871-81. [PubMed: 27241183] 
69. Mäkinen M, Löyttyniemi E, Koskinen M, et al. Serum 25-hydroxyvitamin D concentrations at birth in children screened for HLA-DQB1 conferred risk for type 1 diabetes. J Clin Endocrinol Metab 2019; 104: 2277-85. [PubMed: 30657906]

70. Munger KL, Levin LI, Massa J, Horst R, Orban T, Ascherio A. Preclinical serum 25hydroxyvitamin D levels and risk of type 1 diabetes in a cohort of US military personnel. Am J Epidemiol 2013; 177: 411-19. [PubMed: 23380046]

71. Gorham ED, Garland CF, Burgi AA, et al. Lower prediagnostic serum 25-hydroxyvitamin D concentration is associated with higher risk of insulin-requiring diabetes: a nested case-control study. Diabetologia 2012; 55: 3224-27. [PubMed: 22955995]

72. Mäkinen M, Mykkänen J, Koskinen M, et al. Serum 25-hydroxyvitamin D concentrations in children progressing to autoimmunity and clinical type 1 diabetes. J Clin Endocrinol Metab 2016; 101: 723-29. [PubMed: 26695863]

73. Norris JM, Lee HS, Frederiksen B, et al. Plasma 25-hydroxyvitamin D concentration and risk of islet autoimmunity. Diabetes 2018;67: 146-54. [PubMed: 29061729]

74. Andersson B, Swolin-Eide D, Magnusson P, Albertsson-Wikland K. Vitamin D status in children over three decades - do children get enough vitamin D? Bone reports 2016; 5: 150-52. [PubMed: 28326354]

75. Schleicher RL, Sternberg MR, Lacher DA, et al. The vitamin D status of the US population from 1988 to 2010 using standardized serum concentrations of 25-hydroxyvitamin D shows recent modest increases. Am J Clin Nutr 2016; 104: 454-61. [PubMed: 27385610]

76. Calder PC, Grimble RF. Polyunsaturated fatty acids, inflammation and immunity. Eur J Clin Nutr 2002; 56: S14-19. [PubMed: 12142955]

77. De Caterina R, Madonna R, Massaro M. Effects of omega-3 fatty acids on cytokines and adhesion molecules. Curr Atheroscler Rep 2004; 6: 485-91. [PubMed: 15485595]

78. Fritsche K Fatty acids as modulators of the immune response. Annu Rev Nutr 2006; 26: 45-73. [PubMed: 16848700]

79. Niinisto S, Takkinen HM, Uusitalo L, et al. Maternal dietary fatty acid intake during pregnancy and the risk of preclinical and clinical type 1 diabetes in the offspring. Br J Nutr 2014; 111: 895-903. [PubMed: 24589042]

80. Sørensen IM, Joner G, Jenum PA, Eskild A, Stene LC. Serum long chain n-3 fatty acids (EPA and DHA) in the pregnant mother are independent of risk of type 1 diabetes in the offspring. Diabetes Metab Res Rev 2012; 28: 431-38. [PubMed: 22396195]

81. Niinisto S, Takkinen HM, Erlund I, et al. Fatty acid status in infancy is associated with the risk of type 1 diabetes-associated autoimmunity. Diabetologia 2017; 60: 1223-33. [PubMed: 28474159]

82. Norris JM, Yin X, Lamb MM, et al. Omega-3 polyunsaturated fatty acid intake and islet autoimmunity in children at increased risk for type 1 diabetes. JAMA 2007; 298: 1420-28. [PubMed: 17895458]

83. Norris JM, Kroehl M, Fingerlin TE, et al. Erythrocyte membrane docosapentaenoic acid levels are associated with islet autoimmunity: the diabetes autoimmunity study in the young. Diabetologia 2014; 57: 295-304. [PubMed: 24240437]

84. Miller MR, Yin X, Seifert J, et al. Erythrocyte membrane omega-3 fatty acid levels and omega-3 fatty acid intake are not associated with conversion to type 1 diabetes in children with islet autoimmunity: the diabetes autoimmunity study in the young (DAISY). Pediatr Diabetes 2011; 12: 669-75. [PubMed: 21435137]

85. Sichert-Hellert W, Wicher M, Kersting M. Age and time trends in fish consumption pattern of children and adolescents, and consequences for the intake of long-chain n-3 polyunsaturated fatty acids. Eur J Clin Nutr 2009; 63: 1071-75. [PubMed: 19536160]

86. Cusack LK, Smit E, Kile ML, Harding AK. Regional and temporal trends in blood mercury concentrations and fish consumption in women of child bearing age in the united states using NHANES data from 1999-2010. Environ Health 2017; 16: 10. [PubMed: 28212649]

87. Zhang Z, Fulgoni VL, Kris-Etherton PM, Mitmesser SH. Dietary intakes of EPA and DHA omega-3 fatty acids among US childbearing-age and pregnant women: an analysis of NHANES 2001-2014. Nutrients 2018; 10: 416. 
88. Cnop M, Foufelle F, Velloso LA. Endoplasmic reticulum stress, obesity and diabetes. Trends Mol Med 2012; 18: 59-68. [PubMed: 21889406]

89. Eizirik DL, Miani M, Cardozo AK. Signalling danger: endoplasmic reticulum stress and the unfolded protein response in pancreatic islet inflammation. Diabetologia 2013; 56: 234-41. [PubMed: 23132339]

90. Marre ML, James EA, Piganelli JD. Beta cell ER stress and the implications for immunogenicity in type 1 diabetes. Front Cell Dev Biol 2015; 3: 67. [PubMed: 26579520]

91. Lamb MM, Yin X, Barriga K, et al. Dietary glycemic index, development of islet autoimmunity, and subsequent progression to type 1 diabetes in young children. J Clin Endocrinol Metab 2008; 93: 3936-42. [PubMed: 18682514]

92. Lamb MM, Frederiksen B, Seifert JA, Kroehl M, Rewers M, Norris JM. Sugar intake is associated with progression from islet autoimmunity to type 1 diabetes: the diabetes autoimmunity study in the young. Diabetologia 2015; 58: 2027-34. [PubMed: 26048237]

93. Powell ES, Smith-Taillie LP, Popkin BM. Added sugars intake across the distribution of US children and adult consumers: 1977-2012. J Acad Nutr Diet 2016; 116: 1543-50. [PubMed: 27492320]

94. Wittekind A, Walton J. Worldwide trends in dietary sugars intake. Nutr Res 2014; 27: 330-45.

95. Czoli CD, Jones AC, Hammond D. Trends in sugary drinks in Canada, 2004 to 2015: a comparison of market sales and dietary intake data. Public Health Nutr 2019; 22: 2723-28. [PubMed: 31270002]

96. Op de Beeck A, Eizirik DL. Viral infections in type 1 diabetes mellitus-why the $\beta$ cells? Nat Rev Endocrinol 2016; 12: 263-73. [PubMed: 27020257]

97. Green J, Casabonne D, Newton R. Coxsackie B virus serology and Type 1 diabetes mellitus: a systematic review of published case-control studies. Diabet Med 2004; 21: 507-14. [PubMed: 15154932]

98. Richardson SJ, Morgan NG. Enteroviral infections in the pathogenesis of type 1 diabetes: new insights for therapeutic intervention. Curr Opin Pharmacol 2018; 43: 11-19. [PubMed: 30064099]

99. Laitinen $\mathrm{OH}$, Honkanen H, Pakkanen O, et al. Coxsackievirus B1 is associated with induction of $\beta$ cell autoimmunity that portends type 1 diabetes. Diabetes 2014; 63: 446-55. [PubMed: 23974921]

100. Oikarinen S, Tauriainen S, Hober D, et al. Virus antibody survey in different European populations indicates risk association between coxsackievirus B1 and type 1 diabetes. Diabetes 2014;63: 655-62. [PubMed: 24009257]

101. Stene LC, Rewers M. Immunology in the clinic review series; focus on type 1 diabetes and viruses: the enterovirus link to type 1 diabetes: critical review of human studies. Clin Exp Immunol 2012; 168: 12-23. [PubMed: 22385232]

102. Honkanen H, Oikarinen S, Nurminen N, et al. Detection of enteroviruses in stools precedes islet autoimmunity by several months: possible evidence for slowly operating mechanisms in virusinduced autoimmunity. Diabetologia 2017; 60: 424-31. [PubMed: 28070615]

103. Vehik K, Lynch KF, Wong MC, et al. Prospective virome analyses in young children at increased genetic risk for type 1 diabetes. Nat Med 2019; 25: 1865-72. [PubMed: 31792456]

104. Oikarinen S, Martiskainen M, Tauriainen S, et al. Enterovirus RNA in blood is linked to the development of type 1 diabetes. Diabetes 2011; 60: 276-79. [PubMed: 20943747]

105. Cinek O, Stene LC, Kramna L, et al. Enterovirus RNA in longitudinal blood samples and risk of islet autoimmunity in children with a high genetic risk of type 1 diabetes: the MIDIA study. Diabetologia 2014; 57: 2193-200. [PubMed: 25047648]

106. Stene LC, Oikarinen S, Hyöty H, et al. Enterovirus infection and progression from islet autoimmunity to type 1 diabetes: the diabetes and autoimmunity study in the young (DAISY) Diabetes 2010;59: 3174-80. [PubMed: 20858685]

107. Jääskeläinen AJ, Nurminen N, Kolehmainen P, et al. No association between Ljungan virus seropositivity and the $\beta$-cell damaging process in the Finnish type 1 diabetes prediction and prevention study cohort. Pediatr Infect Dis J 2019; 38: 314-16. [PubMed: 30346370]

108. Tapia G, Bøås H, de Muinck EJ, et al. Saffold virus, a human cardiovirus, and risk of persistent islet autoantibodies in the longitudinal birth cohort study MIDIA. PLoS One 2015; 10: e0136849. [PubMed: 26317929] 
109. Kondrashova A, Nurminen N, Patrikainen M, et al. Influenza A virus antibodies show no association with pancreatic islet autoantibodies in children genetically predisposed to type 1 diabetes. Diabetologia 2015; 58: 2592-95. [PubMed: 26253765]

110. Ruiz PLD, Tapia G, Bakken IJ, et al. Pandemic influenza and subsequent risk of type 1 diabetes: a nationwide cohort study. Diabetologia 2018; 61: 1996-2004. [PubMed: 29934759]

111. Kramna L, Kolarova K, Oikarinen S, et al. Gut virome sequencing in children with early islet autoimmunity. Diabetes Care 2015;38: 930-33. [PubMed: 25678103]

112. Zhao G, Vatanen T, Droit L, et al. Intestinal virome changes precede autoimmunity in type I diabetes-susceptible children. Proc Natl Acad Sci USA 2017; 114: e6166-E6175. [PubMed: 28696303]

113. Lee HS, Briese T, Winkler C, et al. Next-generation sequencing for viruses in children with rapidonset type 1 diabetes. Diabetologia 2013; 56: 1705-11. [PubMed: 23657799]

114. Kim KW, Horton JL, Pang CNI, et al. Higher abundance of enterovirus A species in the gut of children with islet autoimmunity. Sci Rep 2019; 9: 1749. [PubMed: 30741981]

115. Rasmussen T, Wits $\varnothing$ E, Tapia G, Stene LC, Rønningen KS. Self-reported lower respiratory tract infections and development of islet autoimmunity in children with the type 1 diabetes high-risk HLA genotype: the MIDIA study. Diabetes Metab Res Rev 2011; 27: 834-37. [PubMed: 22069269]

116. Ponsonby AL, Pezic A, Cochrane J, et al. Infant anthropometry, early life infection, and subsequent risk of type 1 diabetes mellitus: a prospective birth cohort study. Pediatr Diabetes 2011; 12: 313-21. [PubMed: 21615650]

117. Beyerlein A, Wehweck F, Ziegler AG, Pflueger M. Respiratory infections in early life and the development of islet autoimmunity in children at increased type 1 diabetes risk: evidence from the BABYDIET study. JAMA Pediatr 2013; 167: 800-07. [PubMed: 23818010]

118. Beyerlein A, Donnachie E, Jergens S, Ziegler AG. Infections in early life and development of type 1 diabetes. JAMA 2016; 315: 1899-901. [PubMed: 27139064]

119. Lönnrot M, Lynch KF, Elding Larsson H, et al. Respiratory infections are temporally associated with initiation of type 1 diabetes autoimmunity: the TEDDY study. Diabetologia 2017; 60: 193140. [PubMed: 28770319]

120. Tapia G, Størdal K, Mårild K, et al. Antibiotics, acetaminophen and infections during prenatal and early life in relation to type 1 diabetes. Int J Epidemiol 2018; 47: 1538-48. [PubMed: 29868838]

121. Allen DW, Kim KW, Rawlinson WD, Craig ME. Maternal virus infections in pregnancy and type 1 diabetes in their offspring: Systematic review and meta-analysis of observational studies. Rev Med Virol 2018; 28: e1974. [PubMed: 29569297]

122. Bach JF. The hygiene hypothesis in autoimmunity: the role of pathogens and commensals. Nat Rev Immunol 2018; 18: 105-20. [PubMed: 29034905]

123. Cardwell CR, Stene LC, Joner G, et al. Birth order and childhood type 1 diabetes risk: a pooled analysis of 31 observational studies. Int J Epidemiol 2011; 40: 363-74. [PubMed: 21149280]

124. Radon K, Windstetter D, Solfrank S, et al. Exposure to farming environments in early life and type 1 diabetes: a case-control study. Diabetes 2005; 54: 3212-16. [PubMed: 16249447]

125. Virtanen SM, Takkinen HM, Nwaru BI, et al. Microbial exposure in infancy and subsequent appearance of type 1 diabetes mellitus-associated autoantibodies: a cohort study. JAMA Pediatr 2014; 168: 755-63. [PubMed: 24957949]

126. Bøås H, Tapia G, Sødahl JA, Rasmussen T, Rønningen KS. Enterobius vermicularis and risk factors in healthy Norwegian children. Pediatr Infect Dis J 2012; 31: 927-30. [PubMed: 22531241]

127. Bager P, Vinkel Hansen A, Wohlfahrt J, Melbye M. Helminth infection does not reduce risk for chronic inflammatory diseasein a population-based cohort study. Gastroenterology 2012; 142 : 55-62. [PubMed: 21983081]

128. Kilkkinen A, Virtanen SM, Klaukka T, et al. Use of antimicrobials and risk of type 1 diabetes in a population-based mother-child cohort. Diabetologia 2006; 49: 66-70. [PubMed: 16344923]

129. Hviid A, Svanstrom H. Antibiotic use and type 1 diabetes in childhood. Am J Epidemiol 2009; 169: 1079-84. [PubMed: 19318617] 
130. Clausen TD, Bergholt T, Bouaziz O, et al. Broad-spectrum antibiotic treatment and subsequent childhood type 1 diabetes: a nationwide danish cohort study. PLoS One 2016; 11: e0161654. [PubMed: 27560963]

131. Mikkelsen KH, Knop FK, Vilsboll T, Frost M, Hallas J, Pottegard A. Use of antibiotics in childhood and risk of type 1 diabetes: a population-based case-control study. Diabet Med 2017; 34: 272-77. [PubMed: 27646695]

132. Kemppainen KM, Vehik K, Lynch KF, et al. Association between early-life antibiotic use and the risk of islet or celiac disease autoimmunity. JAMA Pediatr 2017; 171: 1217-25. [PubMed: 29052687]

133. Haupt-Jørgensen M, Morgen CS, Jess T, et al. Maternal antibiotic use during pregnancy and type 1 diabetes in children-a national prospective cohort study. Diabetes Care 2018; 41: e155-57. [PubMed: 30327353]

134. Morgan E, Halliday SR, Campbell GR, Cardwell CR, Patterson CC. Vaccinations and childhood type 1 diabetes mellitus: a meta-analysis of observational studies. Diabetologia 2016; 59: 23743. [PubMed: 26564178]

135. Beyerlein A, Strobl AN, Winkler C, et al. Vaccinations in early life are not associated with development of islet autoimmunity in type 1 diabetes high-risk children: Results from prospective cohort data. Vaccine 2017; 35: 1735-41. [PubMed: 28268073]

136. Vaarala O, Jokinen J, Lahdenkari M, Leino T. Rotavirus vaccination and the risk of celiac disease or type 1 diabetes in finnish children at early life. Pediatr Infect Dis J 2017; 36: 674-75. [PubMed: 28399059]

137. Perrett KP, Jachno K, Nolan TM, Harrison LC. Association of rotavirus vaccination with the incidence of type 1 diabetes in children. JAMA Pediatr 2019; 173: 280-82. [PubMed: 30667473]

138. Rogers MAM, Basu T, Kim C. Lower incidence rate of type 1 diabetes after receipt of the rotavirus vaccine in the United States, 2001-2017. Sci Rep 2019; 9: 7727. [PubMed: 31197227]

139. Hemming-Harlo M, Lähdeaho ML, Mäki M, Vesikari T. Rotavirus vaccination does not increase type 1 diabetes and may decrease celiac disease in children and adolescents. Pediatr Infect Dis J 2019; 38: 539-41. [PubMed: 30986791]

140. Viskari H, Ludvigsson J, Uibo R, et al. Relationship between the incidence of type 1 diabetes and maternal enterovirus antibodies: time trends and geographical variation. Diabetologia 2005;48: 1280-87. [PubMed: 15902401]

141. Viskari H, Ludvigsson J, Uibo R, et al. Relationship between the incidence of type 1 diabetes and enterovirus infections in different European populations: results from the EPIVIR project. J Med Virol 2004; 72: 610-17. [PubMed: 14981763]

142. Howard SG. Exposure to environmental chemicals and type 1 diabetes: an update. J Epidemiol Community Health 2019;73: 483-88. [PubMed: 30862699]

143. Salo HM, Koponen J, Kiviranta H, et al. No evidence of the role of early chemical exposure in the development of $\beta$-cell autoimmunity. Environ Sci Pollut Res Int 2019; 26: 1370-78. [PubMed: 30426368]

144. Kato K, Wong LY, Jia LT, Kuklenyik Z, Calafat AM. Trends in exposure to polyfluoroalkyl chemicals in the U.S. population: 1999-2008. Environ Sci Technol 2011; 45: 8037-45. [PubMed: 21469664]

145. Cohen AJ, Brauer M, Burnett R, et al. Estimates and 25-year trends of the global burden of disease attributable to ambient air pollution: an analysis of data from the global burden of diseases study 2015. Lancet 2017; 389: 1907-18. [PubMed: 28408086]

146. Hidayat K, Zou SY, Shi BM. The influence of maternal body mass index, maternal diabetes mellitus, and maternal smoking during pregnancy on the risk of childhood-onset type 1 diabetes mellitus in the offspring: Systematic review and meta-analysis of observational studies. Obes Rev 2019; 20: 1106-20. [PubMed: 31090253]

147. Magnus MC, Tapia G, Olsen SF, et al. Parental smoking and risk of childhood-onset type 1 diabetes. Epidemiology 2018; 29: 848-56. [PubMed: 30074542]

148. Stewart CJ, Ajami NJ, O'Brien JL, et al. Temporal developmentof the gut microbiome in early childhood from the TEDDY study. Nature 2018; 562: 583-88. [PubMed: 30356187] 
149. Vatanen T, Franzosa EA, Schwager R, et al. The human gut microbiome in early-onset type 1 diabetes from the TEDDY study. Nature 2018; 562: 589-94. [PubMed: 30356183]

150. Niedzwiecki MM, Walker DI, Vermeulen R, Chadeau-Hyam M, Jones DP, Miller GW. The exposome: molecules to populations. Annu Rev Pharmacol Toxicol 2019; 59: 107-27. [PubMed: 30095351]

151. Hastie T, Tibshirani R, Friedman J. The elements of statistical learning, (2nd edn.) New York: Springer, 2009. 


\section{Search strategy and selection criteria}

We searched PubMed for English language articles published from Jan 1, 2000 to Dec 31 2019 , using the search terms "type 1 diabetes" or "diabetes autoimmunity" in combination with the terms "perinatal factors", "cesarean section", "birthweight", "growth", "body-mass index", "infant diet", "breastfeeding", "cow's milk", "complementary feeding", "cereals", "gluten”, "fibre", "vitamin D","omega-3 fatty acids", "dietary sugars", "glycemic index", "sugar sweetened beverages", "virus", "enterovirus", "infection", "hygiene hypothesis", "crowding”, "day care”, "parasites", "antibiotics", "vaccinations", "toxins", and "maternal smoking". We also searched the reference lists of articles identified by this search strategy and selected those we judged relevant. We limited our review of environmental factors to those articles describing findings from prospective studies and large high-quality retrospective studies when prospective studies were not available. In situations in which there were multiple articles on the topic from the same study, we selected the most recent article for review. To search for population data that could explain the changing incidence of type 1 diabetes, we used the above search terms in combination with the terms including "trends", "change over time", and "prevalence". We selected references for inclusion on the basis of quality, relevance, and priority, given limitations on the number of references that could be cited. 


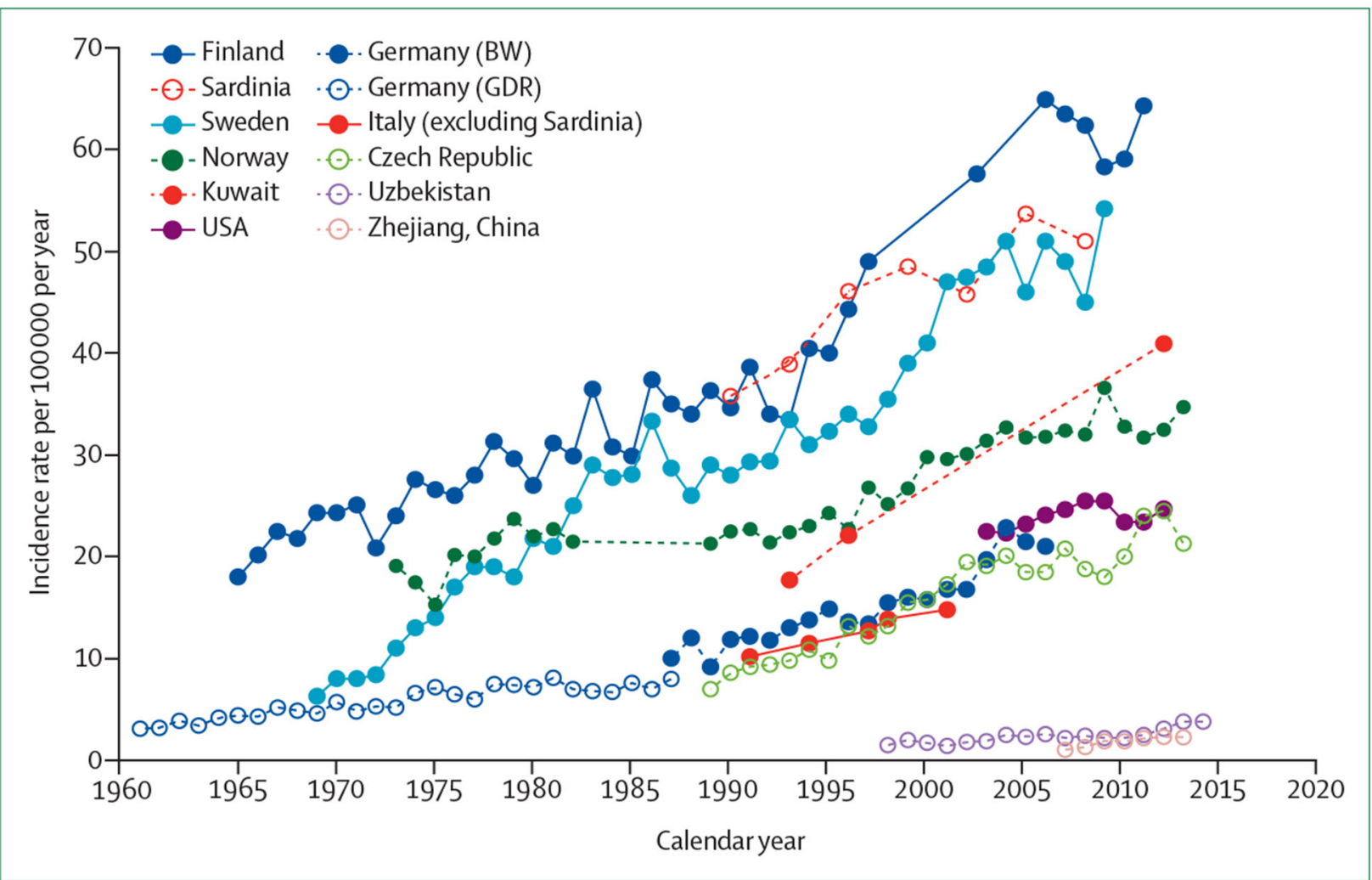

Figure 1: Time trends in incidence of type 1 diabetes

Published data taken from references listed in the appendix pp 1,5-6. GDR=German

Democratic Republic (former Eastern Germany). BW=Baden-Württemberg. 

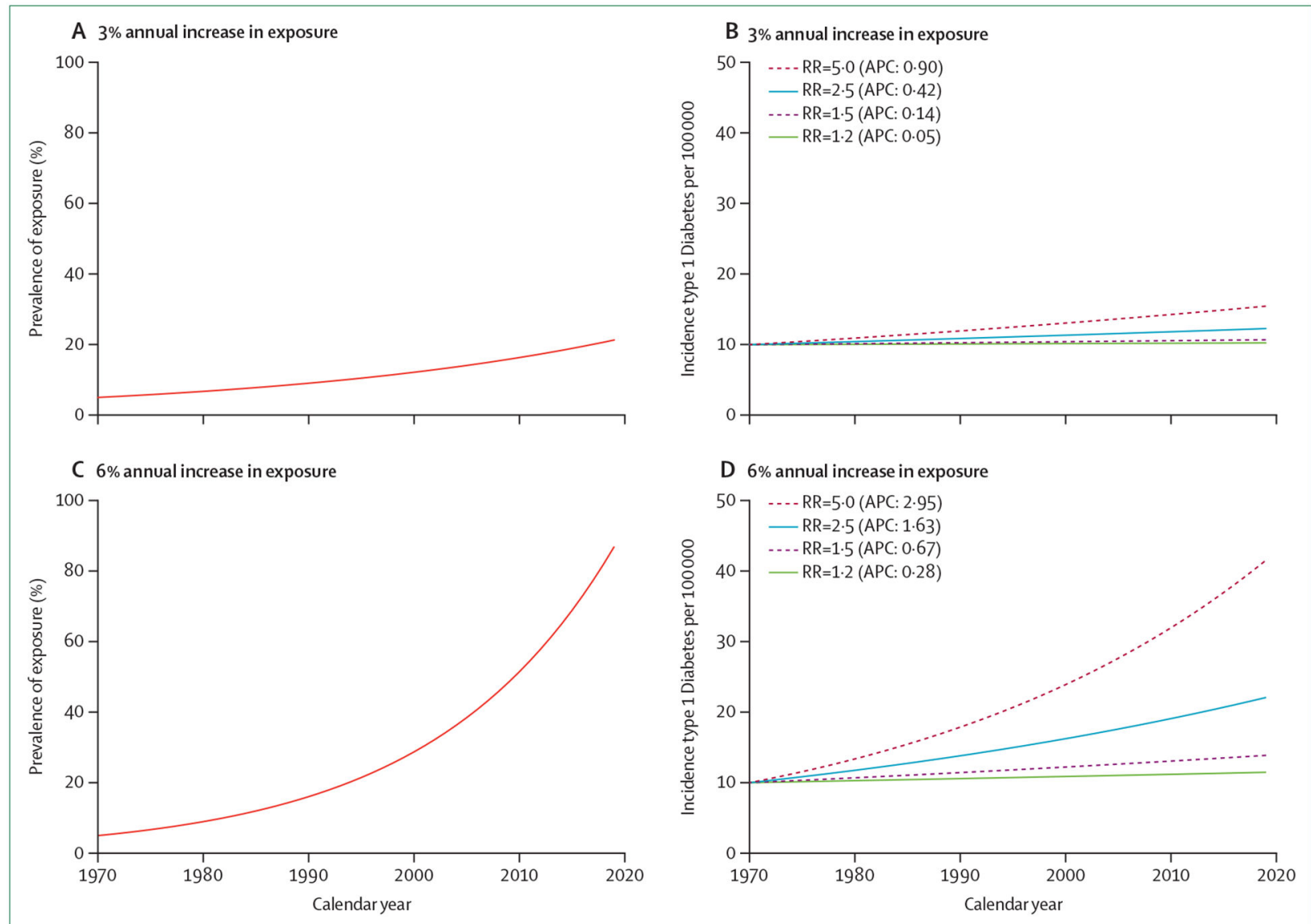

Figure 2: Increasing type 1 diabetes incidence explained by single risk factor under different hypothetical scenarios

(A) and (C) show prevalence of exposure over time with constant annual increase of $3 \%$ or 6\% (from a baseline of 5\%). (B) and (D) show the expected corresponding incidence trends in type 1 diabetes and annual percentage change caused by an exposure under simulated scenarios, where it confers a constant incidence rate ratio, or relative risk (ie, the incidence rate in the exposed group relative to the unexposed group) between 1.2 and 5.0. Baseline type 1 diabetes incidence was arbitrarily set to 10 per 100000 person-years, and the incidence assumed constant at this rate for unexposed people. More details about the methods and additional results are shown in the appendix pp 1-5. APC $=$ annual percentage change. $\mathrm{RR}=$ rate ratio. 


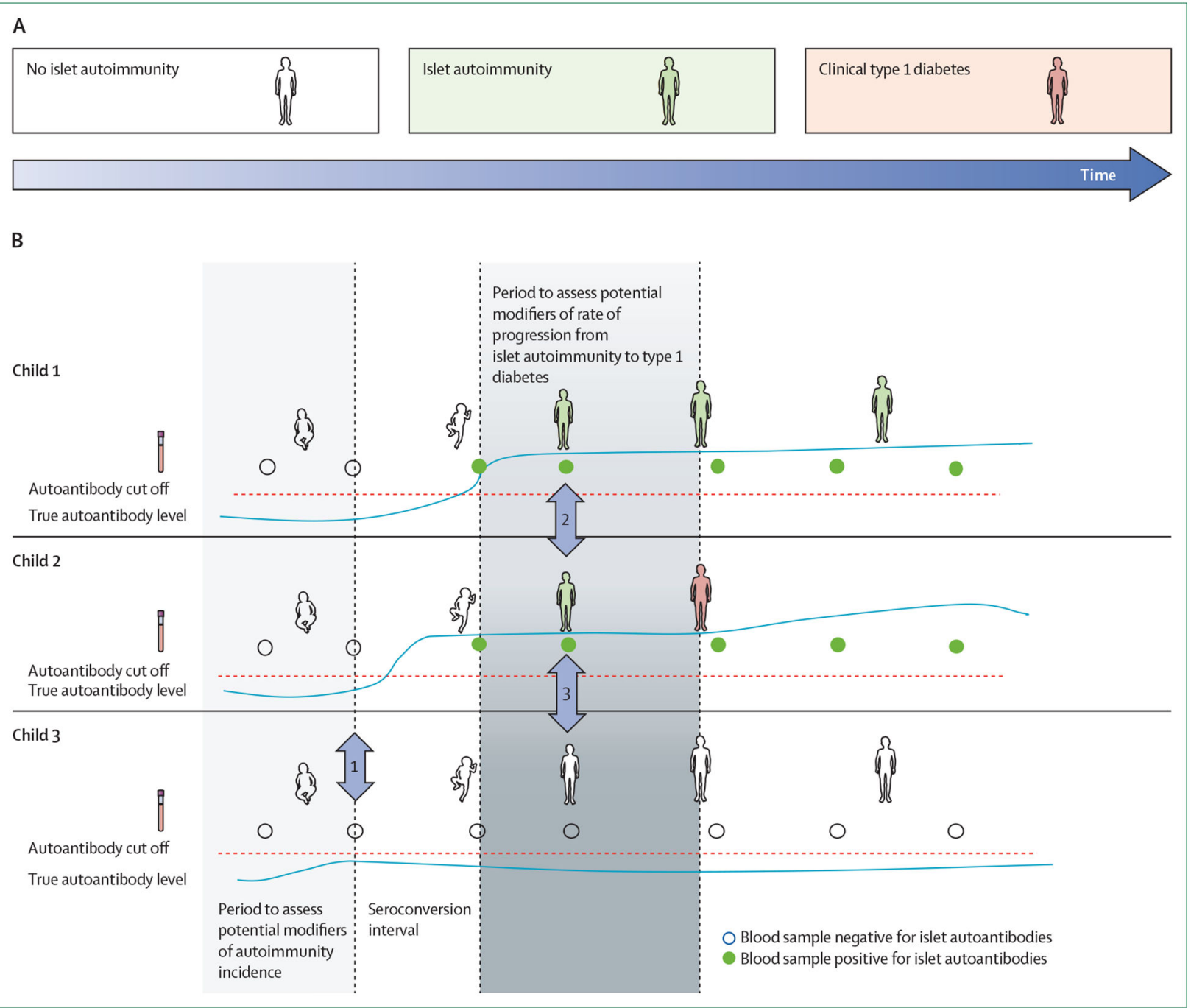

Figure 3: Differentiating factors influencing transitions in the natural history of type 1 diabetes (A) Natural history of type 1 diabetes can be divided into two major transitions: first, from autoantibody negative to persistently positive (green, usually for multiple islet autoantibodies), and the second from islet autoimmunity to clinical type 1 diabetes. (B) Analysing samples to disentangle factors influencing the first or second transition is complex. We observe snapshots of longitudinal development and made useful simplifications. For assessment of factors modifying the incidence islet autoantibody seroconversion, exposures in the (light grey) period before seroconversion in islet autoimmunity cases (child 1 and 2) are compared with the corresponding period in children who do not seroconvert during the same follow-up time (child 3) - eg, vertical arrow 1 . For assessment of factors modifying the rate of progression from islet autoimmunity to clinical type 1 diabetes, exposure must be studied in the (darker grey) period after seroconversion, but before type 1 diabetes. Exposure in children developing type 1 diabetes is compared with the same period for children who do not develop type 1 diabetes during the same follow-up period-eg, vertical arrow 2. This principle applies to cohort studies and nested case-control studies. Any difference in exposure between child 2 and 3 in the (dark grey) period after 
seroconversion eg, vertical arrow 3-could be influenced by reverse causation if involving biomarkers or other measures of exposure that could conceivably be influenced by autoimmunity. The true time of seroconversion is normally not observed, but occurs in the seroconversion interval, between the last negative and the first positive serial blood sample. 